\title{
EDITORIAL
}

\section{Inauguración XVIII Congreso de Obstetricia y Ginecología Discurso del Presidente}

\begin{abstract}
Se reúne hoy de nuevo, alborozadamente, la gran familia de los Gineco-Obstetras Colombianos. Y lo hace en momentos en que parecen mejorar las viscisitudes de la Patria, con fe en su futuro y como una reafirmación de su permanente vocación de servicio a la comunidad. Porque si ha habido en el país grupo medico o disciplina científica que se caracterice por su sensibilidad y por su interés en los problemas de salud que afectan la calidad de vida de sus compatriotas, nuestra especialidad ha sido, sin lugar a dudas, abanderada y en muchas ocasiones pionera de programas que han trascendido los límites mismos de la práctica profesional y han producido cambios fundamentales tanto en la formación académica de los nuevos médicos como en las políticas de salud en el país. Prueba de ello es la historia de nuestros Congresos Nacionales. Cuando uno repasa sus temarios, y yo lo he hecho recientemente con emocionada reverencia, no hay uno solo de los 18 eventos que en sus ponencias oficiales no haya incluido preferencialmente aquellos aspectos que en su momento han representado un peligro o aún una franca agresión para el bienestar de la mujer colombiana y del hijo que lleva en sus entrañas. Desde el primer Congreso Colombiano realizado en Bogotá en 1953, hasta este decimoctavo que iniciamos hoy bajo el ambiente cordial y la acogida generosa de la Puerta de Oro de Colombia, aparecen en su agenda, como una constante, el cáncer ginecológico en especial del cuello uterino, la toxemia gravídica, el estudio y manejo de la esterilidad conyugal, y ya desde 1957 en el tercer congreso celebrado en Ibagué, aparecen interesantísimos estudios sobre Morbilidad y Mortalidad Materno Infantil, descubriéndose así una línea de acción que movilizó a las Sociedades filiales, se extendió a las Facultades de Medicina, e interesó al propio Ministerio de Salud a través de su División Materno Infantil iniciándose así una benéfica cooperación entre dos sectores tradicionalmente ajenos entre sí, cuando no aparentemente antagónicos y recelosos de sus propias actividades. Fruto de este trabajo conjunto fue la adopción del Enfoque de Riesgo, que basado en tales investigaciones colaborativas, permitió la organización y el funcionamiento de los niveles de atención en el Grupo Materno Infantil tres años antes de que la Organización Mundial de la Salud le diera carta de ciudadanía a la estrategia de la Atención Primaria. Esta política de concertación, que tanto ha influido en la reducción de las tasas de mortalidad materna en nuestro país, fue oficializada hace 10 años en el decimocuarto Congreso realizado en Cartagena. Allí se fijaron compromisos y estrategias que fortalecieron la relación entre los niveles de planeación, de normatización y de ejecución, dieron origen a nuevos programas de investigación operacional que han dejado sus frutos en la adopción oficial, dentro del Sistema Nacional de Salud, de las metodologías allí probadas, y han estimulado la creación de redes de investigación y de servicios entre las cuales merece destacarse la Red Nacional de Perinatología. Y al lado de estas acciones de tanta trascendencia social, aparece el interés por el amplio campo de la Endocrinología Ginecológica, incorporada por primera vez en los temas oficiales en el quinto Congreso efctuado en 1963 en Medellín y expuesta allí por ese prohombre de nuestra especialidad que fue el profesor Pedro Nel Cardona. ¿ Yqué decir de la acogida y del estímulo que los congresos dieron al trascendental tema de la dinámica de población y sus múltiples facetas en la „planificación familiar, en el aborto y sus inocultables consecuencias, en la sexualidad del adolescente?.
\end{abstract}

Se estimuló entonces el interés por el estudio de tan apasionante problemática y así como en el área obstétrica las actividades anteriormente reseñadas nos permitieron trascender del limitado campo de una actividad rutinariamente asistencial y desempeñar un papel protagónico en los programas de salud materna, asimismo, el interés allí generado, creó una conciencia de nuestra responsabilidad al respecto y estimuló las acciones tendientes a crear estrategias de intervención en dichos campos. En el área de la reproducción por ejemplo, propició la iniciación de colegas que posteriormente han podido desarrollar el potencial de sus capacidades en centros de reconocida prestancia internacional. Pero, además, y en el mismo campo, podemos afirmar que en el país se han creado respetables escuelas y se han podido desarrollar y aplicar en nuestro medio tecnologías aparentemente reservadas al mundo industrializado, aportando aún innovaciones gracias al estudio, al tesón y por qué no decirlo a la audacia de nuestros profesionales.

La experiencia adquirida por Fecolsog como actor y muchas veces como gestor en las actividades comentadas, le ha valido el reconocimiento internacional y la ha capacitado para desempeñarse decorosa- 
mente en el concierto de las Asociaciones similares de América Latina. En el Informe que me permitiré presentar a la Asamblea Ordinaria de la Federación, analizaré detalladamente este hecho. Pero por la distinción que representa para nuestra Federación, he creído necesario hacer partícipe de ella a la audiencia aquí presente. En efecto, la Federación Latinoamericana de Sociedades de Obstetricia y Ginecología (FLASOG), que agrupa a todas las Sociedades o Federaciones Nacionales de la Región, tiene establecidos dentro de su funcionamiento, como estrategia de trabajo, los llamados Grupos Regionales. Nuestra Federación hace parte, en unión de las Sociedades de Bolivia, Ecuador, Perú y Venezuela, del Grupo Regional Bolivariano, el cual desde 1987 ha sido coordinado por Fecolsog,que en desarrollo de esa función ha dirigido las investigaciones multicéntricas realizadas en los cinco países Miembros y las ha presentado en el ámbito de los Congresos Latinoamericanos, siendo el único grupo en desarrollar estas metodologías de trabajo, la cual ha sido elogiosamente reconocida por la Asamblea de Flasog como ejemplo de cooperación internacional digna de imitarse, exaltando de paso el liderazgo de Fecolsog en el proceso.

Este breve y obviamente incompleto recordatorio de una trayectoria meritísima me sirve señores, para reafirmar ante ustedes que nuestra Federación, nacida en el histórico templo de la Villa del Rosario de Cúcuta en 1967 como ente aglutinador de las varias Sociedades Regionales, y como una necesidad de reconocimiento y de apoyo a las mismas, lejos de haber sido una entelequia legal o un nuevo organismo competidor de sus filiales, ha tenido un derrotero claro y consecuente: ser, ante todo y por sobre todo, un agente de desarrollo de las Sociedades regionales, estimulando u orientando las actividades que cada una de ellas haya escogido como líneas de acción que las identifique y fortalezca.

Esta mirada hacia el pasado, que me he permitido esbozar ante ustedes como un justo homenaje a quienes han sido los artífices de tantos logros, nos estimula y compromete. Se abren campos promisorios para que nuestra Federación, científicamente acreditada y financieramente fortalecida, se lance a realizar programas que se traduzcan en acciones que nos permitan participar activamente en el campo de la salud dentro del escenario nacional. Creo firmemente que ha llegado el momento de constituir diversos comités, secciones o grupos de trabajo en diferentes áreas de la especialidad tales como la Oncología Ginecológica, la Mortalidad materna y Perinatal, la dinámica poblacional, la Patología mamaria, las enfermedades médicas del embarazo, y trascendiendo del campo puramente clínico, del complejo tema de la formación del especialista en sus diversos aspectos, el científico, el ético, y los relacionados con su desempeño profesional y sus posibilidades de empleo. Estos organismos, que aglutinarían a los especialistas nacionales de acuerdo a sus preferencias y expertismo, representarán una inyección vivificante en el devenir de nuestra Federación y constituirán sistemas de canalización adecuados y oportunos para mantener una presencia verdaderamente actuante de Fecolsog ante los múltiples cambios que día a día se presentan como consecuencia de la celeridad de los cambios sociales y de los avances tecnológicos.

Pero, además, se yergue ante nosotros algo que dejó de ser una amenaza para convertirse en una realidad. Me refiero a los nuevos sistemas de Atención Médica Integral, léase Medicina Prepagada, que como una nueva actividad de poderosos grupos financieros y amparada por la innegable realidad de los altos costos de la atención médica, han surgido desordenadamente entre nosotros, creando confusas situaciones en cuyos orígenes no se hizo oportunamente presente el cuerpo médico nacional. Solo hasta hace poco tiempo, y ante el impacto que a la ya menguada práctica privada ocasionó el incremento del sistema, se produjo la reacción de los especialistas, quienes agrupados por sus Sociedades Científicas, lograron constituir un cuerpo homogéneo cuyos delegados han sido decorosamente reconocidos como interlocutores oficiales ante dichas compañías y han merecido un tratamiento deferente y respetuoso de su parte, facilitando así un proceso de negociaciones que aspira lograr mutuos beneficios de las partes y que ha sido facilitado por un ambiente de cordialidad y de buena voluntad. En este proceso nuestra Federación, como máxima entidad que agrupa a todas las Sociedades Regionales, ha estado presente. Y debe seguir estándolo, manteniendo una unidad monolítica entre sus miembros, demandando de ellos comprensión y paciencia ante los posibles tropiezos del progreso y aportando con solidaridad y buen sentido un contingente inteligente deliberante pero conciente de la responsabilidad histórica del momento. Aquí tendrá Fecolsog una línea de acción ardua y laboriosa pero debe perseverar en el camino de los acuerdos con dignidad y con firmeza.

Señores asistentes:

Circunstancias suficientemente conocidas de todos ustedes obligaron a la Junta Directiva que tengo la honra de presidir, a orientar los destinos de nuestra Federación durante el último cuatrenio. Aspiramos no haber defraudado la confianza que nos otorgaron en 1987 en la ciudad de Pereira, generosa y unánimemente reafirmada en la Asamblea Extraordinaria celebrada en Bogotá en noviembre de 1990. Ha sido en verdad una labor gratificante no solo por el privilegio de haber compartido las responsabilidades con colegas de la distinción, inteligencia, honestidad e invaluable don de consejo de Edgard Cobo, de Jaime Barrios, de 
Fernando Cardona, de Enrique Archila, de Germán Uriza, de Carlos Quintero, Ariel Orrego, Carlos Saieh y Hermes Pumarejo, sino por la acogida que siempre tuvieron las iniciativas de la Junta en las Sociedades Regionales y por las estimulantes actividades en las cuales hicieron partícipe a la directiva nacional. Al término de nuestro mandato, miramos con optimismo el porvenir, y en cuanto a mí personalmente se refiere, no puedo ocultar un inmodesto sentimiento de satisfacción y de orgullo al ver como tras de 11 años de vinculación ininterrumpida en las labores de la Junta, puedo entregar como su Presidente una organización sólida, estable y en condiciones óptimas para acometer nuevas e impostergables acciones que la hagan digna intérprete de las inquietudes de sus Miembros.

EL SEÑOR PRESIDENTE DEL COMITE ORGANIZADOR DEL CONGRESO ME HA CONCEDIDO EL HONOR DE DAR LA BIENVENIDA A LOS DISTINGUIDOS CONFERENCISTAS NACIONALES Y EXTRANJEROS QUE EN FORMA GENEROSA HAN RESPONDIDO AL LLAMADO DE SUS COLEGAS COLOMBIANOS. RECIBAN TODOS ELLOS EL TESTIMONIO DE NUESTRA GRATITUD, DE NUESTRO APRECIO Y DE NUESTRA SINCERA AMISTAD.

Señor Presidente y Señores Miembros del Comité Organizador del Congreso: Quienes hemos sido testigos del laborioso proceso de preparación de este Congreso, no podemos menos de expresarles nuestra admiración y nuestra gratitud: aceptaron ustedes el reto de su organización concientes de su inexperiencia pero también y en qué manera, de su inquebrantable voluntad de éxito y de su valía profesional. Y hoy, entregan a sus colegas Colombianos el fruto de su esfuerzo, de su superación y de la fuerza arrolladora de su juventud.

Este certamen, señores, es una demostración de la vitalidad de nuestra Patria.Es una reşpuesta digna a los detractores de su nombre. No ocultamos nuestras debilidades y miserias pero reivindicamos todo lo grande y todo lo noble que tenemos en la gloriosa tradición de su historia.

iViva Colombia! 